Pollution

\section{Land contamination and renal dysfunction}

\section{Jarup}

\section{Cause for concern?}

L and contaminated by current or historical industrial activity is com-mon in many countries, and the influence of soil pollutants on the environment often causes concern. It has been recognised that not only may the quality of the environment suffer as a consequence of the pollution, but there may also be specific problems for human health associated with contaminated land, as well as a consequent economic burden.

During recent decades it has become increasingly obvious that the kidney is adversely affected by an array of chemicals. ${ }^{2}$ Human exposure to (nephrotoxic) chemicals may result from industrial emissions and other environmental pollution, from several naturally occurring substances as well as from medicines. Some of these chemicals may cause acute injury to the kidneys, whereas others may result in chronic renal damage and eventually end stage renal failure. For example, a recent Swedish study showed excess risk of end stage renal disease (ESRD) in a population living in the vicinity of cadmium emitting battery plants. ${ }^{3}$

A paper by Staples et al, in this issue of Occupational and Environmental Medicine, reports on signs of kidney tubular dysfunction in persons exposed to hexachlorobutadiene (HCBD). ${ }^{4}$ The findings raise several issues, which are important for the assessment of environmental health risks in general and for kidney disease risk in particular.

Firstly, it is very important to consider the potential exposure pathways. A common misconception is that soil concentration of a toxic substance equals human exposure. Exposure may be defined as "the contact of a chemical, physical, or biological agent with the outer boundary of an organism". ${ }^{5}$ Exposure is often defined as a function of concentration and time:

\footnotetext{
"An event that occurs when there is contact at a boundary between a human and the environment with a contaminant of a specific concentration for an interval of time"
}

Thus, the key word is "contact". Direct contact between toxicants in soil and human "boundary" is possible via ingestion, for example via hand to mouth behaviour or so-called pica (eating of substances other than food), which is not uncommon among young children. Exposure may also occur via intake of drinking water from private boreholes or inhalation of dust particles or gases emanating from the contaminated land. Another possible exposure pathway is via intake of vegetables grown on contaminated land. This has been shown in areas polluted by heavy metals (cadmium in particular) in Belgium, where there was a correlation between cadmium in soil, in selected vegetables, such as celery and beans, and urinary cadmium level, which is a good indicator of long term cadmium exposure. ${ }^{7}$ There was also an inverse correlation between cadmium in soil and vegetables, and kidney function, assessed by creatinine clearance.

Secondly, other exposures also need to be taken into consideration. Commonly, contaminated land is a result of past or ongoing industrial activity, resulting in emissions to air and/or water, which in turn lead to land contamination. Another possibility is the storing of toxic waste in landfill sites, from which toxicants may escape into the ambient air or water. For example, Halton Borough, described in the paper by Staples et al, is indeed located in a heavily industrialised area, where emissions of several known nephrotoxicants, such as mercury and lead, have taken place over a long period of time. Thus, the population in the area has most likely been exposed to a mixture of renal toxicants over a long period of time, including potential exposure from landfill sites containing industrial waste. There is almost no information on kidney effects resulting from human exposure to multiple chemicals. ${ }^{2}$ This is a major problem, since people living in industrial areas are generally exposed to more than one substance, not only related to the environment, but also via individual intake of food and medicines.

Thirdly, it should be noted that although markers of tubular dysfunction may be good indicators of early kidney damage, they are not specific to any particular exposure. Such markers may be elevated for a number of reasons, including environmental or occupational exposure as well as infections and medicine intake. It is thus important to assess individual exposure to all potential causative agents, in order to draw the correct conclusions.

Is land contamination a cause for concern in relation to renal disease? This will depend on the toxic properties, the exposure pathways, and the dose absorbed by the exposed population. It is clear that for some persistent chemicals, such as heavy metals, there may indeed be cause for concern. Cadmium is of particular concern, because of the very long biological half life (10-15 years) which means that also relatively low daily intake for a long time, may result in a body burden where renal dysfunction begins to appear. This has been recognised by the European Union, which is currently evaluating recent studies to assess whether low level cadmium exposure may cause renal damage at lower levels than previously anticipated. $^{8}$ Furthermore, since cadmium is readily taken up by a variety of grain and vegetables, crops grown on cadmium contaminated land may be a source of human exposure. For other renal toxicants, the exposure pathway may be more difficult to establish, but there are certainly examples of human exposure related to land contaminated by other heavy metals, such as lead and mercury.

Renal tubular dysfunction may progress to glomerular dysfunction and ESRD, which is a major public health problem, causing both suffering to the affected individuals and a severe burden on health services providing dialysis and kidney transplantation. Data on human health effects associated with exposure to most renal toxicants are sparse. Considering the potentially large effects on public health, there is a need for further research, in particular on low level exposure to persistent chemicals and the potential progress of tubular dysfunction to more severe kidney disease. There is also a need to investigate effects associated with combined exposure to two or more renal toxicants, a research area that is virtually unexplored.

Occup Environ Med 2003;60:461-462

Correspondence to: Dr L Jarup, The Small Area Health Statistics Unit (SAHSU), Department of Epidemiology and Public Health, Imperial College London, Faculty of Medicine, St Mary's Campus, 16 South Wharf Road, London W2 1PF, UK; I.jarup@imperial.ac.uk 


\section{REFERENCES}

1 Vegter JJ, Lowe J, Kasamas H, eds. Sustainable management of contaminated land: an overview. Austrian Federal

Environment Agency, on behalf of CLARINET, 2002

2 International Programme on Chemica Safety. Environmental health criteria 119. Principles and methods for the assessment of nephrotoxicity associated with exposure to chemicals. Geneva: World Health Organisation, 1991.
3 Hellström L, Elinder CG, Dahlberg B, et al. Cadmium exposure and end-stage renal disease. Am J Kidney Dis 2001;38:1001-8.

4 Staples B, Howse MLP, Mason H, et al. Land contamination and urinary abnormalities: cause for concern? Occup Environ Med 2003;60:463-7.

5 Berglund $M$, Elinder CG, Järup L. Human exposure assessment-an introduction. Geneva: WHO, 2002 (also available on the Internet: http://www.imm.ki.se/PDF/ HEAboken.pdf).
6 NRC. Human exposure assessment for airborne pollutants. Advances and opportunities. Washington, DC: National Research Council, National Academy Press, 1991.

7 Staessen JA, Lauwerys RR, Ide G, et al. Renal function and historical environmental cadmium pollution from zinc smelters. Lancet pollution from zinc s

8 Järup L, Hellström L, Alfvén T, et al. Low level cadmium exposure and early kidney damage - the OSCAR study. Occup Environ Med 2000;57:668-72.

\section{Clinical Evidence-Call for contributors}

Clinical Evidence is a regularly updated evidence based journal available worldwide both as a paper version and on the internet. Clinical Evidence needs to recruit a number of new contributors. Contributors are health care professionals or epidemiologists with experience in evidence based medicine and the ability to write in a concise and structured way.

Currently, we are interested in finding contributors with an interest in the following clinical areas:

Altitude sickness; Autism; Basal cell carcinoma; Breast feeding; Carbon monoxide poisoning; Cervical cancer; Cystic fibrosis; Ectopic pregnancy; Grief/bereavement; Halitosis; Hodgkins disease; Infectious mononucleosis (glandular fever); Kidney stones; Malignant melanoma (metastatic); Mesothelioma; Myeloma; Ovarian cyst; Pancreatitis (acute); Pancreatitis (chronic); Polymyalgia rheumatica; Post-partum haemorrhage; Pulmonary embolism; Recurrent miscarriage; Repetitive strain injury; Scoliosis; Seasonal affective disorder; Squint; Systemic lupus erythematosus; Testicular cancer; Varicocele; Viral meningitis; Vitiligo

However, we are always looking for others, so do not let this list discourage you.

Being a contributor involves:

- Appraising the results of literature searches (performed by our Information Specialists) to identify high quality evidence for inclusion in the journal.

- Writing to a highly structured template (about 2000-3000 words), using evidence from selected studies, within 6-8 weeks of receiving the literature search results.

- Working with Clinical Evidence Editors to ensure that the text meets rigorous epidemiological and style standards.

- Updating the text every eight months to incorporate new evidence.

- Expanding the topic to include new questions once every 12-18 months.

If you would like to become a contributor for Clinical Evidence or require more information about what this involves please send your contact details and a copy of your CV, clearly stating the clinical area you are interested in, to Claire Folkes (cfolkes@bmigroup.com).

\section{Call for peer reviewers}

Clinical Evidence also needs to recruit a number of new peer reviewers specifically with an interest in the clinical areas stated above, and also others related to general practice. Peer reviewers are health care professionals or epidemiologists with experience in evidence based medicine. As a peer reviewer you would be asked for your views on the clinical relevance, validity, and accessibility of specific topics within the journal, and their usefulness to the intended audience (international generalists and health care professionals, possibly with limited statistical knowledge). Topics are usually 2000-3000 words in length and we would ask you to review between 2-5 topics per year. The peer review process takes place throughout the year, and our turnaround time for each review is ideally 10-14 days.

If you are interested in becoming a peer reviewer for Clinical Evidence, please complete the peer review questionnaire at www.clinicalevidence.com or contact Claire Folkes (cfolkes@bmigroup.com). 